\title{
Biological Stability and Antimicrobial Activity Analysis of Antagonism Actinomycete SC-04 Fermentation Fluid
}

\author{
WENBIN LI and ZENGBO LI* \\ College of Chemical and Biological Engineering, \\ Taiyuan University of Science and Technology, Taiyuan 030021, P.R. China. \\ Corresponding author E-mail: 115078363@qq.com \\ http://dx.doi.org/10.13005/ojc/320112
}

(Received: December 15, 2015; Accepted: March 13, 2016)

\begin{abstract}
The present study has been aimed to assess biological stability of the antagonism actinomycete SC-04 fermentation fluid isolated from the Qinghai-Tibet Plateau soil of China. Aspects on antimicrobial effect to pathogenic fungi and polarity of antimicrobial substance have also been characterized. The results showed that the fermentation fluid of antagonism actinomycete SC-04 was stable under room temperature less than $90 \mathrm{~d}$, it had a remarkable thermal stability under $70^{\circ} \mathrm{C}$ less than $30 \mathrm{~min}$ or under $100^{\circ} \mathrm{C}$ less than $10 \mathrm{~min}$, and also had a pH stability among 4.0 and 12.0. Moreover, it was UV stable if irradiated less than $30 \mathrm{~min}$. In addition, this fermentation broth was soluble in water and also in solvent, and could be extracted using ethyl acetate. Furthermore, the extract of SC-04 fermentation fluid by ethyl acetate had relative widely antimicrobial spectrum to the most pathogenic fungi, especially for Alternaria solani and Phytophthora capsici. Thus, the SC-04 fermentation fluid could be used for the production of antibiotics and develope for biological pesticide.
\end{abstract}

Key words: Actinomycete SC-04, Fermentation, Antimicrobial activity.

\section{INTRODUCTION}

Soil borne fungal and oomycete plant pathogens are important determinants of the dynamics of plant populations in natural environments and in agricultural environments, they include Fusarium spp., Phytophthora spp., Pythium spp. and Gaeumannomyces graminis etc. Despite low initial densities of inoculum in soil, these pathogens can cause complete destruction of plants, and occasionally, total loss of yield ${ }^{1-2}$.

The term "biological control" and its abbreviated synonym "biocontrol" have been used in different fields of biology, but in plant pathology, this term is applied for the use of microbial antagonists (the biological control agent or BCA) to suppress diseases. Most narrowly, biological control refers 
to the suppression of a single pathogen (or pest) by a single antagonist in a single cropping system ${ }^{3}$. Microorganisms as BCAs are widely reported, and in some cases, their modes of action against the plant pathogen have been elucidated. One of the best studied modes of action of bacterial BCAs is the antagonism mediated by different compounds with antifungal properties ${ }^{4}$. Most microbes produce and secrete one or more compounds with antibiotic activity $^{5-6}$. The strategies separate biocontrol compounds or antibiotic is one of the first important steps in control plant pathogenic fungi. There is an effective strategy, which could be considered curative, uses microorganisms as biopesticides and resembles in some important respects the approach of chemical pesticide treatment ${ }^{7}$. However, this method is better than the chemical pesticide treatment. Microorganism is easily broken down by nature and not pollute the environment, with low energy consumption and less investment, and can produce huge economic and social benefits. Therefore, some researchers have begun to make great efforts in research and development of biopesticides by activation of disease-resistance genes, or antibiotic production by beneficial microorganisms ${ }^{8-10}$.

The Qinghai-Tibet Plateau of China was the origin center of some wild crops such as barley ${ }^{11}$, and maybe there are some valuable resources in the soil, indicating the possibility of selecting unique materials highly tolerant to biotic stresses, such as pepper phytophthora plight. In this context, actinomycete has received considerable attention as biocontrol agent, the actinomycete SC-04 was isolated from the farmland soil of eastern QinghaiTibet Plateau of China ${ }^{12}$. The aim of this investigation was to analyse biological stability and antimicrobial activity to farmland pathogenic fungi of antagonism actinomycete SC-04 fermentation fluid, and provide the basis for the research and development of biopesticide or antibiotics using microorganism.

\section{MATERIALS AND METHODS}

\section{Bacterium, fungi and culture}

One strain of antagonism actinomycete SC-04 was isolated from the soil on the Tibetan Plateau in China, the strain was cultured at $37^{\circ} \mathrm{C}$ on plate starch nitrate (PSN) medium. Sixteen fungi namely Phytophthora capsici, Alternaria solani, Gibberella zeae, Botrytis cinerea Pers, Colletotrichum lagenarium, Fusarium oxysporum, C. gloeosporioides, F. oxysporum f.sp cucumerinum, F. graminearum, Pyricularia oryzae, C. higginsianum Sacc, A. brassicicola, Botrytis cinerea, B. cinere, F. oxysporum. f.sp. vasinfectum, F. oxysporium Schl were purchased from the China center of industrial culture collection (CICC), they were maintained on potato dextrose agar (PDA) medium at $28^{\circ} \mathrm{C}$.

\section{Antagonism actinomycete SC-04 fermentation}

The SC-04 actinomycete was activated on the agar slant culture at $28{ }^{\circ} \mathrm{C}$ for $72 \mathrm{~h}$, then inoculated into $50 \mathrm{ml}$ of fermentation media in a 250 $\mathrm{ml}$ Erlenmeyer flask where it was shaken at $150 \mathrm{rpm}$ using an orbital shaker and maintained at $28^{\circ} \mathrm{C}$ in the dark for $24 \mathrm{~h}$ before the media was fermented. After the sub-culture, $5 \mathrm{ml}$ suspension SC-04 actinomycete was inoculated in $50 \mathrm{ml}$ fermentation media and maintained at $28^{\circ} \mathrm{C}$ in the dark shaking at $150 \mathrm{rpm}$ for 7 days. Fermentation broth was filtrated with a 0.22 im membrane filter after sterilization using filter paper, the cell-free filtrate obtained and it was saved for the following experiment.

The composition of fermentation medium ( $\mathrm{g}$ $\mathrm{L}^{-1}$ ): soybean powder, 20; sugar, 3; peptone, 2; starch, 10; yeast extract, $2 ; \mathrm{NaCl}, 2 ; \mathrm{K}_{2} \mathrm{HPO}_{4}, 1 ; \mathrm{ZnSO}_{4}, 0.01$; $\mathrm{FeSO}_{4} \cdot 7 \mathrm{H}_{2} \mathrm{O}, 0.01 ; \mathrm{MgSO}^{2} \cdot 7 \mathrm{H}_{2} \mathrm{O}, 0.5 ; \mathrm{CaCO}_{3}$, 2. The medium $\mathrm{pH}$ was adjusted to $7.2 \pm 0.1$ with $\mathrm{NaOH}$ or $\mathrm{HCl}$.

\section{Stability analysis of antagonism actinomycete SC-04 fermentation filtrate}

The antimicrobial activity tests were carried out. $5 \mathrm{ml}$ cell-free fermentation filtrate was transferred into $50 \mathrm{ml} \mathrm{PDA}$ medium that was cooled to $50^{\circ} \mathrm{C}$, after mixture and solidification, the mycelium biscuit of Phytophthora capsici with the diameter $7 \mathrm{~mm}$ was put onto the mixed plate, they were co-cultured at $28^{\circ} \mathrm{C}$ for $72 \mathrm{~h}$, then the diameter of mycelium biscuit was measured using vernier caliper (measured twice cross, averaged). Free cell-free fermentation filtrate plate as control plate, and each treatment repeated three times. Relative antimicrobial rate (RAR) of a given parameter was calculated as the diameters on the mixed plate (treatment) relative to control plate. Loss rate of activity (LRA) was calculated as 
the RAR of treatment relative to control [i.e., LAR = (RAR under control - RAR under treatment)/RAR under control].

Determination of preservation time stability: After the fermentation filtrate preserved for $1 \mathrm{~d}$, $7 \mathrm{~d}, 30 \mathrm{~d}$ and $90 \mathrm{~d}$ under room temperature, the antimicrobial activity test was done as above method using Phytophthora capsici as indicator, the original fermentation filtrate as control. Preservation time stability was determined according to the LRA of the antimicrobial activity test.

Determination of thermal stability: The fermentation filtrate treated under $70^{\circ} \mathrm{C}$ and $100^{\circ} \mathrm{C}$ for $10 \mathrm{~min}, 30 \mathrm{~min}$ and $60 \mathrm{~min}$, respectively, and under $121^{\circ} \mathrm{C}$ for $30 \mathrm{~min}$, the fermentation filtrate under room temperature $\left(25^{\circ} \mathrm{C}\right)$ as control. The thermal stability was determined according to the LRA of the above antimicrobial activity test.

Determination of acid and alkali stability: The fermentation filtrate $\mathrm{pH}$ was adjusted to 1.0, 2.0, 3.0, 4.0, 5.0, 6.0, 7.0, 8.0, 9.0, 10.0, 11.0, 12.0, 13.0 and 14.0, respectively, with $\mathrm{NaOH}$ or $\mathrm{HCl}$. They were kept under $25^{\circ} \mathrm{C}$ for $6 \mathrm{~h}$ and then the $\mathrm{pH}$ adjusted back to the original value 8.3. The acid and alkali stability was determined according to the LRA of the above antimicrobial activity test.

Determination of UV stability: The fermentation filtrate and PDA mixed plate (fermentation filtrate:PDA medium was 1:10) was prepared as above, the treatment was the plate irradiated by ultraviolet light for 20 min on the super clean bench before the antimicrobial activity test,

Table 1: Effect of preservation time on the antimicrobial activity of SC-04 fermentation filtrate

\begin{tabular}{lcc}
\hline $\begin{array}{l}\text { Preservation } \\
\text { time (d) }\end{array}$ & $\begin{array}{c}\text { RAR } \\
\text { (\%) }\end{array}$ & $\begin{array}{c}\text { LRA } \\
(\%)\end{array}$ \\
\hline 0 & 100 & 0 \\
1 & 100 & 0 \\
7 & 97.3 & 2.7 \\
30 & 91.7 & 8.3 \\
90 & 85.2 & 14.8 \\
\hline
\end{tabular}

irradiation free plate was control. The UV stability was determined according to the LRA.

\section{Polarity analysis of antimicrobial substance}

$50 \mathrm{ml}$ fermentation fluid was added into a $250 \mathrm{ml}$ Erlenmeyer flask containing the same volume petroleum ether, chloroform, ethyl acetate and n-butyl alcohol, respectively. After mixed and shaked on the orbital shaker under room temperature until completely blended, the mixture was stood for the night. The antimicrobial activity of the upper organic phase and the bottom water phase was determined according to Sun et al. ${ }^{13}$.

\section{Determination antimicrobial spectrum of SC-04 fermentation filtrate}

After the ethyl acetate fermentation crude extract dissolved with methanol, the antimicrobial activity to the above 16 pathogenic fungi was determined according to Sun et al. ${ }^{13}$.

\section{RESULTS AND DISCUSSION}

Stability analysis of antagonism actinomycete SC-04 fermentation filtrate

Preservation time stability: The RAR of the actinomycete SC-04 fermentation filtrate showed a significant decrease along with increasing preservation time, and the LRA was increased with increasing preservation time (Table 1). And the largest increase in LRA appeared after 90 days preservation, with the LRA $14.8 \%$, it showed the actinomycete SC-04 was stable under room temperature within $90 \mathrm{~d}$.

Table 2: Effect of temperature on the antimicrobial activity of SC-04 fermentation filtrate

\begin{tabular}{lccc}
\hline $\begin{array}{l}\text { Temp. } \\
\left({ }^{\circ} \mathbf{C}\right)\end{array}$ & $\begin{array}{c}\text { Treated } \\
\text { time(min) }\end{array}$ & $\begin{array}{c}\text { RAR } \\
(\%)\end{array}$ & $\begin{array}{c}\text { LRA } \\
(\%)\end{array}$ \\
\hline Control(25) & 0 & 85.4 & 0 \\
70 & 10 & 72.9 & 14.6 \\
& 30 & 62.5 & 26.8 \\
& 60 & 62.4 & 26.9 \\
100 & 10 & 68.8 & 19.4 \\
& 30 & 43.8 & 48.7 \\
& 60 & 41.7 & 51.2 \\
121 & 30 & 31.3 & 63.3 \\
& & & \\
\hline
\end{tabular}


Thermal stability: With the increasing treated temperature, the RAR of the actinomycete SC-04 fermentation filtrate showed a significant decrease, the LRA was increased with increasing treated temperature (Table 2), i.e. under $70^{\circ} \mathrm{C}$ and $100^{\circ} \mathrm{C}$ for $10 \mathrm{~min}$, the RAR (LRA) was $72.9 \%$ (14.6\%) and $68.8 \%(19.4 \%)$ respectively. And under the same temperature, the RAR decreased and the LRA increased with increasing treated time, for instance, under $70^{\circ} \mathrm{C}$ for $10 \mathrm{~min}, 30 \mathrm{~min}$ and $60 \mathrm{~min}$ the RAR (LRA) was $72.9 \%$ (14.6\%), 62.5\% (26.8\%) and $62.4 \%$ (26.9). These changing trends were the same with the change under $100^{\circ} \mathrm{C}$, and under these two temperatures more than 30 min the RAR and LRA was significantly difference with control. However, the remarkable difference was under $121^{\circ} \mathrm{C}$ for $30 \mathrm{~min}$, with the RAR $31.3 \%$ and the LRA $63.3 \%$. It indicated that the pre-treatment of the actinomycete SC-04 fermentation filtrate should be controlled under

Table 3: Effect of different pH on the antimicrobial activity of SC-04 fermentation filtrate

\begin{tabular}{lcc}
\hline pH value & RAR (\%) & LRA (\%) \\
\hline Control (8.3) & 85.4 & 0 \\
1.0 & 10.4 & 75.0 \\
2.0 & 27.1 & 68.3 \\
3.0 & 31.3 & 63.3 \\
4.0 & 68.7 & 19.5 \\
5.0 & 70.8 & 17.1 \\
6.0 & 81.2 & 4.9 \\
7.0 & 81.2 & 4.9 \\
8.0 & 85.4 & 0 \\
9.0 & 85.3 & 0.1 \\
10.0 & 81.2 & 4.9 \\
11.0 & 77.1 & 9.7 \\
12.0 & 72.9 & 14.6 \\
13.0 & 52.1 & 39.0 \\
14.0 & 41.7 & 51.2 \\
\hline
\end{tabular}

appropriate temperature and time, eg. under $70^{\circ} \mathrm{C}$ less than 30 min or under $100^{\circ} \mathrm{C}$ less than $10 \mathrm{~min}$.

Acid and alkali stability: The RAR (LRA) of the actinomycete SC-04 fermentation filtrate showed significant decrease (increase) when the $\mathrm{pH}$ value less than 3.0 and more than 12.0. Moreover, there was no obvious difference when the $\mathrm{pH}$ value among 4.0 and 12.0 , and the LRA less than $20 \%$. Therefore, under the premise that it does not affect the activity of SC-04 fermentation filtrate, the rheological properties could be controlled by changing the $\mathrm{pH}$ value, in order to facilitate separation and extraction of SC-04 fermentation products.

UV stability: As shown in the Fig. 1, there was no visible difference between UV irradiated and control, with the RAR $75.7 \%$ and $76.4 \%$ for irradiated and control respectively. It indicated that after UV irradiated for $30 \mathrm{~min}$ the antimicrobial activity of SC04 fermentation filtrate didn't change significantly, and these active substance was basically stable to ultraviolet.

The establishment of the fermentation filtrate pre-treatment method

After the fermentation, the fermentation medium contained a variety of metabolites in addition to antibiotics. These impurities not only led to viscosity of fermentation filtrate increased, but also

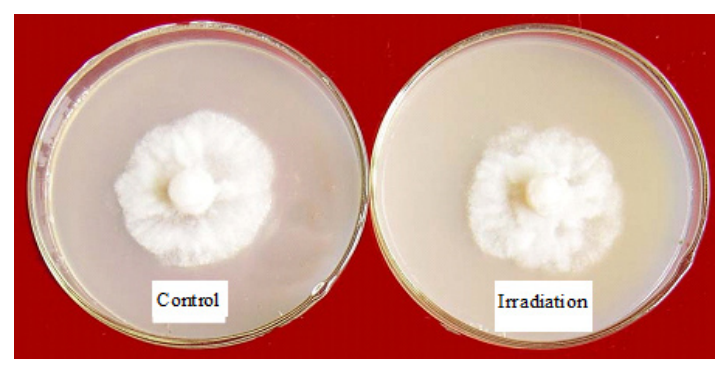

Fig. 1: Result of UV irradiation

Table 4: Results of extraction on fermentation filtrate

\begin{tabular}{lcccc}
\hline Extraction liquid & \multicolumn{4}{c}{ DIZ (mm) } \\
& Petroleum ether & Chloroform & Ethyl acetate & n-Butyl alcohol \\
\hline Colour of extraction liquid & Yellow & Faint yellow & Red brown & Orange \\
Upper organic phase & 0 & 10 & 21 & 0 \\
Bottom water phase & 20 & 16 & 10 & 25 \\
\hline
\end{tabular}


affected subsequent extraction operation as well. So, in order to improve the rheological properties of fermentation filtrate, remove impurities that affect subsequent purification operation and make the extraction go smoothly, it was often necessary to pre-treat fermentation filtrate. On the other side, there was some inorganic salts in the fermentation filtrate, which will directly affect the quality of the products (eg. Increased ash content), accordingly pre-treatment should remove inorganic ions, such as $\mathrm{Ca}^{2+}, \mathrm{Fe}^{3+}, \mathrm{Mg}^{2+}$ etc. However, for the physical and chemical properties of this antimicrobial active ingredients we know little in our knowledge, therefore there was no drastic treatment in the pre-treatment of fermentation filtrate.

The present results of fermentation filtrate stability test indicated that the strain of actinomycete SC-04 had a remarkable thermal and $\mathrm{pH}$ stability. Thus, the appropriate fermentation filtrate pretreatment method should be: the original fermentation broth was filtrated or centrifuged at $5000 \mathrm{r} \mathrm{min}^{-1}$, the $\mathrm{pH}$ of fluid was adjusted to 6.0 , then centrifuged again after stood for $10 \mathrm{~min}$ under $70^{\circ} \mathrm{C}$, this fluid was the fermentation fluid.

\section{Polarity analysis of antimicrobial substance}

It was shown in the Table 4, the antimicrobial substance of SC-04 fermentation filtrate could be soluble in organic solvent that has strong polarity, such as chloroform and ethyl acetate, and the extraction effect of ethyl acetate was better, with the diameter of inhibition zone (DIZ) of ethyl acetate $20 \mathrm{~mm}$ and chloroform $10 \mathrm{~mm}$. Moreover, it wasn't soluble in organic solvent that has strong polarity nonpolar solvent petroleum ether either the strong polar solvent n-butyl alcohol. According to the principle of similar miscibility, the antimicrobial substance of SC-04 fermentation filtrate possess of a relative strong polarity. This active substance was soluble in water and also soluble in solvent, it may be a fat-soluble and water-soluble antibiotic, and could be extracted using ethyl acetate.

\section{Determination antimicrobial spectrum of SC-04 fermentation filtrate}

The extract of SC-04 fermentation fluid by ethyl acetate had relative widely antimicrobial spectrum (Table 5), it had good inhibitory effect to the most pathogenic fungi except for Pyricularia oryzae, i.c. the DIZ of Alternaria solani and Phytophthora capsici was $32 \mathrm{~mm}$ and $30 \mathrm{~mm}$, respectively.

In conclusion, the present study showed that fermentation filtrate of antagonism actinomycete SC-04 was stable under room temperature less than $90 \mathrm{~d}$. Moreover, it had a remarkable thermal and $\mathrm{pH}$ stability, c.f. it was stable under $70^{\circ} \mathrm{C}$ less than 30 min or under $100^{\circ} \mathrm{C}$ less than $10 \mathrm{~min}$, there was no obvious difference when the $\mathrm{pH}$ value among 4.0 and 12.0 in RAR and LRA, and the LRA less than $20 \%$. In addition, it had relatively UV stability irradiated less than $30 \mathrm{~min}$. Thus, the appropriate pretreatment of antagonism actinomycete SC-04 fermentation broth was as following process: the original fermentation broth should be filtrated or centrifuged at $5000 \mathrm{r} \mathrm{min}^{-1}$, the $\mathrm{pH}$ of fluid was adjusted to 6.0 , then centrifuged again after stood for $10 \mathrm{~min}$ under $70^{\circ} \mathrm{C}$, this fluid

Table 5: Antimicrobial spectrum of SC-04 fermentation fluid aginst pathogenic fungi (mm)

\begin{tabular}{lcclcc}
\hline Pathogenic fungi & DIZ $(\mathbf{m m})$ & Diaphanecity & Pathogenic fungi & DIZ $(\mathbf{m m})$ & Diaphanecity \\
\hline A. solani & 32 & +++ & Gibberella zeae & 20 & +++ \\
F. graminearum & 21 & +++ & Pyricularia oryzae & 0 & - \\
B. cinerea Pers & 25 & +++ & Phytophthora capsici & 30 & ++ \\
C. lagenarium & 19 & +++ & C. higginsianum Sacc & 15 & ++ \\
F. oxysporum & 16 & ++ & B. cinerea & 22 & + \\
F. oxysporium Schl & 20 & + & B. cinere & 25 & ++ \\
C. gloeosporioides & 16 & + & A. brassicicola & 15 & + \\
F. oxysporum f.sp & 12 & +++ & F.f.sp vasinfectum & 18 & ++ \\
cucumerinum & & & & &
\end{tabular}

notes: "+"0"++"0"+++" means inhibition zone eyeable, clear, prutudent, respectively 
was the fermentation fluid used as the antimicrobial activity substance. This active substance was soluble in water and also soluble in solvent, it may be a fat-soluble and water-soluble antibiotic, and could be extracted using ethyl acetate. Furthermore, the extract of SC-04 fermentation fluid by ethyl acetate had relative widely antimicrobial spectrum to the most pathogenic fungi, Alternaria solani and Phytophthora capsici were the most sensitive in the tested pathogenic fungi. Accordingly, the SC04 fermentation fluid had the very high potential for biological pesticide development and utilization value.

\section{ACKNOWLEDGEMENTS}

This work was supported by the National Natural Science Foundation of China (31401319), the Program for the Top Young Academic Leaders of Higher Learning Institutions of Shanxi of China (20151006), Shanxi Province Science Foundation for Youths (2015021146), and the Scientific Research Foundation for Doctoral Scholars of Taiyuan University of Science and Technology of China (HY201301), Youth Fund Projects of Taiyuan University of Science and Technology of China (20070125), (20113008).

\section{REFERENCES}

1. Deacon J.W. Biocontrol Sci. Technol. 1991, 1, 5-20.

2. Pal KK, McSpadden Gardener B. The Plant Health Instructor. 2006, 1-25.

3. Pliego C., Ramos C., de Vicente A., Cazorla F.M. Plant Soil. 2011, 340, 505-520.

4. Haas D., Keel C. Annu. Rev. Phytopathol. 2003, 41, 117-153.

5. Raaijmakers J.M., Vlami M., de Souza J.T. Antonie van Leeuwenhoek, 2002, 81, 537-547.

6. Gross H., Loper J.E. Nat. Prod. Rep. 2009, 26, 1408-1446.

7. Knudsen I.M.B., Hockenhull J., Jensen D.F., Gerhardson B., Hökeberg M., Tahvonen R., Teperi E., Sundheim L., Henriksen B. Eur. J. Plant Pathol. 1997, 103, 775-784.
8. Hoitink H.A.J., Boehm M.J. Annu. Rev. Phytopathol. 1999, 37, 427-446.

9. Maher M., Prasad M., Raviv M. "Organic soilless media components", ed. Raviv M., Lieth J.H. Soilless Culture: Theory and Practice. Elsevier BV, Oxford, p. 459-504 (2008).

10. Cuesta G., García-de-la-Fuente R., Abad M., Fornes F. J. Environ. Manage. 2012, 95, S280-S284.

11. Zhao J., Sun H.Y., Dai H.X., Zhang G.P., Wu F.B. Euphytica, 2010, 172, 395-403.

12. Li Z.B. Thesis for masters degree Northwest $A$ and $F$ University, June 2006.

13. Sun H.Y., Li Z.B., Liu W.X., Wang X.Y., Zhang T.J., Feng Z.J. Asian J. Chem. 2014, 26(1), 298-302. 